\title{
LOS DERECHOS FUNDAMENTALES EN PERSONAS NATURALES Y JURÍDICAS. VALIDACIÓN DE UN INSTRUMENTO, ANÁLISIS DE CONCEPCIONES Y ESTRATEGIA FORMATIVA PARA PROFESIONALES 0 ESTUDIANTES DE DERECHO*
}

\author{
Fundamental rights in natural and legal persons. The validation \\ of an instrument, the analysis of conceptions and the training \\ strategy for professionals or students of law
}

Gustavo Ardila Arrieta**

John Jairo Briceño Martínez ${ }^{* * *}$

José Orlando Ugarte Lizarazo****

Recepción: 18/8/18. Aceptación: 11/01/19

DOI: http://dx.doi.org/10.21017/Rev.Repub.2019.v26.a62

\section{RESUMEN}

Si los derechos humanos y fundamentales se sustentan en la dignidad humana, pero a las personas jurídicas no se les puede aplicar esta figura, no es entendible cómo se llega -por parte de la Corte Constitucional Colombiana, como intérprete de nuestra Carta Política- a otorgársele tales privilegios, generando ello las dudas que impulsan este proceso investigativo, para lo cual se realiza una revisión bibliográfica sobre conceptos como a) persona natural, b) persona jurídica, c) derechos humanos, d) derechos fundamentales, e) dignidad humana y f) ciudadanía. Posteriormente, se describen los resultados obtenidos

* Artículo producto de proyecto de investigación que desarrollaron los autores en el marco académico e investigativo de la Facultad de Educación y el grupo de investigación Culturas Universitarias de la Universidad Antonio Nariño, sede Bogotá D. C.

** Abogado de la Universidad Autónoma Latinoamericana (Colombia) y egresado de la Maestría en Educación de la Universidad Antonio Nariño. Juez decimosegundo penal municipal con funciones de control de garantías de Medellín (Colombia, departamento de Antioquia).

*** Doctor en Tendencias y Aplicaciones de la Investigación Educativa de la Universidad de Granada (España). Director de la Maestría en Educación y del grupo de investigación Culturas Universitarias de la Universidad Antonio Nariño.

**** Doctor en Educación de la Universidad de Minnesota (EUA). Decano de la Facultad de Educación de la Universidad Antonio Nariño. 
al construir y validar mediante criterio de expertos un instrumento para luego indagar en $\mathrm{N}=30$ estudiantes de último semestre de derecho sus concepciones sobre los derechos fundamentales. Se presentan también los progresos de $\mathrm{N}=4$ abogados que participaron de una estrategia formativa para avanzar en sus conocimientos sobre estas temáticas. Se concluye que los estudiantes deben avanzar en sus concepciones sobre estos aspectos, pues se detectan algunos vacíos conceptuales, que no se identifican en los abogados que participaron en la estrategia formativa, los cuales mejoran aún más tras la intervención.

Palabras clave: derechos fundamentales, personas naturales, personas jurídicas, estrategias de enseñanza de los derechos fundamentales.

\begin{abstract}
If human and fundamental rights are based on human dignity, but to the juridical persons can not be applied this figure, it is not understandable how the Colombian Constitutional Court, as interpreter of our Political Constitution, can be granted such privileges, generating doubts that drive this research, for which a bibliographic review was made on concepts such as a) natural person, b) legal entity, c) human rights, d) fundamental rights, e) human dignity and f) citizenship. Subsequently, the obtained results are described by constructing and validating, through expert criteria, an instrument to later investigate in $\mathrm{N}$ $=30$ students of last semester of law their conceptions about fundamental rights. The progress of $\mathrm{N}=4$ lawyers who participated in a training strategy to advance their knowledge on these issues is also presented. It is concluded that students must advance in their conceptions about these aspects, since some conceptual gaps are detected, which are not identified in the lawyers that participated in the training strategy, which improve even more after the intervention.
\end{abstract}

Key-words: fundamental rights, natural persons, legal entities, teaching strategies of fundamental rights.

\title{
INTRODUCCIÓN
}

Los Derechos Humanos son el género y son aquellas prerrogativas que anteceden la conformación y el reconocimiento mismo del Estado a todas las personas humanas. Por su parte, los Derechos Fundamentales son la especie y se constituyen en insumos mínimos necesarios para la existencia plena de cada persona (Ferrajoli, 2010). Ocurre que los primeros solo se predican de los seres humanos (Fayos, 2016), mientras que los segundos permiten aplicación análoga y extensiva a las personas jurídicas. 
Los seres humanos somos personas naturales (Bonilla, 2010), mientras que las jurídicas son las empresas o entidades incorpóreas no biológicas sin vida (Larrea, 2008), pero con derechos fundamentales. Se nos ha dicho por la intérprete constitucional colombiana -y esto se ciñe a lo que han concluido sus homólogas en otros países y en otros doctrinantes sobre el tema (Díaz, 1989)- que ello obedece a que las personas jurídicas se componen, a su vez, de personas naturales y, por ende, la asignación de derechos fundamentales busca materializar esa visión y misión institucional a favor de las personas naturales que les componen (Carballeira, 2002).

Pero al mismo tiempo es la propia Corte la que propone que ambas categorías de derechos, tanto humanos como fundamentales, se fundan en la dignidad humana (Tuvilla, 2009), entendida esta, en términos generales, como el disponer de libertad para gestar y lograr un plan de vida individual de cada quien (sentencia C-143 de 2015, Relatoría Corte Constitucional, Bogotá D. C., Colombia, revisión: 25/3/18). De hecho, cuando aborda los derechos fundamentales en las personas jurídicas, expresamente descarta la procedencia y pertinencia de dignidad humana en esta última categoría, lo que deja entonces dudas sobre esta dicotomía que se genera cuando, parece que una cosa es, pero no es al mismo tiempo (Fayos, 2016). Dentro del ámbito tanto educativo como profesional, según lo que se ha podido evidenciar dentro del marco teórico y la revisión bibliográfica realizada (Ribotta, 2008; López-Barajas y Ruiz, 2000), este asunto no se aborda de forma argumentada, lo que ha llevado a esta investigación a enfrentar grandes retos; el primero a realizar, una revisión bibliográfica sobre la normatividad vigente tanto en el mundo y también cómo se ha abordado desde lo educativo, al encontrarse una escasa evidencia de estrategias educativas y de instrumentos que evalúen este tema; este trabajo se ha centrado en cubrir tres aristas ambiciosas, a saber: la validación de un instrumento, las concepciones y lo formativo; por tanto, se plantean las tres preguntas de investigación: ¿Cómo evaluar tanto la mejora como las concepciones de estudiantes universitarios y profesionales del derecho cuando no hay instrumentos validados sobre derechos fundamentales? ¿Cuáles son las concepciones sobre «derecho fundamental» y cómo se interpreta tanto a personas jurídicas y naturales en estudiantes universitarios de derecho? ¿Cómo contribuir a mejorar las concepciones sobre derecho fundamental en profesionales del derecho?

\section{LOS REFERENTES TEÓRICOS}

\section{Concepciones sobre derechos humanos y la dignidad humana}

La Declaración Universal de los Derechos Humanos, heredera del pensamiento ilustrado y liberal (Mestre, 2016), surge del seno de las Naciones Unidas 
luego del 10 de diciembre de 1948 en París, en cuyos 2 primeros artículos del mismo nos aclaran, por si alguna duda puede quedar, quiénes son los sujetos beneficiarios o destinatarios de dicho postulado normativo; así, en el segundo leemos: «Art. 2. Toda persona tiene todos los derechos y libertades proclamados en esta Declaración, sin distinción alguna de raza, color, sexo, idioma, religión, opinión política o de cualquier otra índole, origen nacional o social, posición económica, nacimiento o cualquier otra condición» (Declaración Universal de los Derechos Humanos).

Así pues, que no nos queda dudas de que estos derechos se aplican y tienen como destinatarios a los seres humanos. Y acudiendo a la definición que hace la Real Academia de la Lengua Española, tenemos que «humano: dicho de un ser: que tiene naturaleza de hombre», «hombre: ser animado racional, varón o mujer», «humanidad: naturaleza humana», «naturaleza humana: conjunto de todos los seres humanos» (Real Academia Española, consultada: 25/3/2018).

El ser humano, que tiene derechos de la misma naturaleza, se presume, ha de ser aquel que nace de mujer, discurso homogéneo y pacífico hasta la fecha. Incluso el Tribunal Constitucional español nos dice que la existencia de ese patrimonio genético es diferenciada en el concebido respecto de la portadora, dado que se entiende como un «tertium» diferente de la madre; esto cuando nos habla de la «persona» (Bueno y Gil, 2011).

Morello (2009, pág. 38) define la persona como «cuerpo humano individual, dotado de cierta peculiaridad en su figura y en sus operaciones; por consiguiente, un aspecto somático y un estilo expresivo y motor».

Según Fayos (2016), se muestra como indubitado que todo ser humano es persona, lo que lo hace sujeto de derechos; siendo titulares de estos las personas físicas por su condición de tales (Escobar, 2005); son conceptos inseparables: «Es la estructura antropo-ontológica propia del ser humano» al decir de Hoyos (2005, pág. 226); se les ha llamado valores y principios inherentes a la «naturaleza humana» (Eggers-Brass, Zajac y Gallego, 2004); y asociados a la especie (Vallegas, Sosa y Guerrero, 1994). Por tanto, entendemos que los derechos humanos se predican de manera exclusiva respecto de los seres humanos por inherencia y definición.

Cuando analizamos la conexión entre estos derechos y la dignidad, definimos los primeros como «demandas de abstención o actuación, derivadas de la dignidad de la persona y reconocidas como legítimas por la comunidad internacional, siendo por ello merecedoras de protección jurídica por el Estado» (Escobar, 2005, pág. 16) y asistimos a una univocidad en la totalidad de los autores revisados en lo referente a este tópico. 
Parafraseando a Fayos (2016), agrega que la persona se define como humana, reconociéndole inherencia «dignitas» a todo hombre como racional que es. Los derechos humanos son demandas derivadas de esa dignidad de la persona, en el escenario de lo Ético y no del derecho positivo (Escobar, 2005). Solo esa dignidad y la naturaleza humana podrían garantizar la eficacia de la Declaración de los Derechos de 1948 (Barp, 2006), que es indivisible (Blázquez, 2003), que su ausencia implica insatisfacción de las garantías personales y que, como sustento de los derechos fundamentales, se constituye en el freno a esas mayorías coyunturales que tanto daño pueden hacer a las minorías fluctuantes (Ollero, 2004).

Cuando esa dignidad se independiza de la religión pasa a sustentar al ser humano en tales prerrogativas, lo cual les genera la autoridad que de ellas se predica (Barranco, 2015); protegiendo a la persona humana contra los vejámenes, provengan de donde provengan y auspiciándole su pleno desarrollo (Nogueira, 2003). Que a su vez, la práctica de los derechos humanos tiende a recuperar la dignidad (Gagneten y Sala, 2004), de donde podemos concluir que no solo le sirve de sustento sino que también se constituye en su objetivo, consolidando los derechos humanos incluso antes de su reconocimiento positivo (Schickendantz, 2009), o como cuando se nos dice que el hombre -como género- deriva su dignidad de su propio ser y de sus cualidades o de las circunstancias que lo rodean; esto según Lacalle (2015) y López-Barajas y Ruiz (2000).

Starck (2010) nos recuerda que esa dignidad humana se impuso por el constituyente alemán como talanquera al desprecio que de ella tuvo el nacionalsocialismo, puntualizando que «la dignidad humana corresponde al ser humano concreto», no siendo posible utilizarle para alcanzar otros fines en la sociedad. Por su parte, De Asís (2007) la sitúa como «referente principal de los valores políticos y jurídicos de la ética pública de la modernidad» (2007, pág. 157); conclusión a la que también llegaron Mestre (2016) y Hoyos (2005).

Nuestra Corte Constitucional, en la sentencia C-143/15, dice de la dignidad humana: «según se desprende del art. 1 Superior, es el fundamento del ordenamiento jurídico, es decir que este concepto es un pilar determinante en el Estado Social de Derecho y en la democracia constitucional, y por tanto de los Derechos Humanos y de los derechos fundamentales en general ${ }^{1}$, y constituye una norma vinculante para toda autoridad». Por ende, los derechos humanos no podrían interpretarse desde una óptica diferente a la del ser humano, ya que es este quien define su naturaleza a través de la dignidad humana (Tuvilla, 2009).

1 Resaltos propios. 


\section{Concepciones sobre los Derechos Fundamentales. De las personas naturales y jurídicas}

Ferrajoli (2010, pág. 19) expone: «son "derechos fundamentales" todos aquellos derechos subjetivos que corresponden universalmente a 'todos' los seres humanos en cuanto datos del status de personas, de ciudadanos o personas con capacidad de obrar; entendiendo por "derecho subjetivo" cualquier expectativa positiva (de prestaciones) o negativa (de no sufrir lesiones) adscrita a un sujeto por una norma jurídica; y por "status" la condición de un sujeto, prevista asimismo por una norma jurídica positiva, como presupuesto de idoneidad para ser titular de situaciones jurídicas y / o autor de los actos que son ejercicio de estas».

Estos derechos se garantizan «expresamente [en] la Constitución sustrayéndolos a [sic] la libertad del legislador» (Rodríguez y Muñiz, 2000, pág. 122), convirtiéndose en fundamento para el desarrollo integral de un sujeto al autodeterminarse, predicable ello solamente de las personas naturales y siempre buscando el interés de las personas individuales, lo que excluiría, por lo tanto, las morales o jurídicas (Rodríguez y Muñiz, 2000).

Para Teruel, Pérez y Raffiotta (2017) se constituyen en los valores que concretan el sistema político; de hecho, incluso cuando refieren a García Pelayo, nos dicen que son los que legitiman su obediencia, constituyéndose en axiomas estimados y aceptados por la generalidad.

Prado (2009, pág. 4) sentencia que «Los derechos fundamentales ya dijimos son derechos humanos positivizados y reconocidos por las constituciones de cada Estado de derecho». Entonces, estos derechos son parte de los humanos, pero institucionalizados o registrados en una determinada Carta Política.

La temática de la división de derechos humanos en categorías de generaciones es también pacífica, así que los de primera generación o llamados «fundamentales» se relacionan con las ideas básicas de los seres humanos, libertad, igualdad, seguridad personal, etcétera; (Mestre, 2016; Klaiber, Zegarra, y Rubio, 2006). Obedecen, pues, a aquellos denominados «individuales, civiles y políticos», «destinados a la protección del ser humano individualmente considerado, contra cualquier agresión de algún organismo público. Constituyen límites al poder estatal» (Colegio24hs, 2004, pág. 6-7).

Tanto el Tribunal Constitucional Federal alemán como su par español exponen que los derechos fundamentales materializan el principio de la Dignidad Humana buscando que por su intermedio se concreten obligaciones respecto del ser humano, como cimiento de la democracia (Villacorta y Villacorta, 2013), por lo que estos derechos se soportan en esa dignidad, solo predicable de las personas naturales. 
Incluso García (2011) habla indistintamente de ambas categorizaciones: derechos humanos y derechos fundamentales. Confusión que no es insólita, ya que cuando se analiza el devenir histórico del derecho constitucional mexicano, y citando al diputado Macías, expone que se confundieron derechos naturales con los fundamentales y políticos (Moreno-Bonett, 2004).

\section{De las personas naturales y jurídicas}

Bonilla (2010, pág. 22) define persona como «la denominación genérica que se da a todos los individuos de la especie humana, iguales en naturaleza y dignidad. Es común afirmar que los seres humanos somos personas, somos hombres o mujeres, somos criaturas en las que se concentran tanto procesos vitales, como actitudes espirituales».

Cuando emula a Juan XXIII, Fayos (2016) puntualiza que en la encíclica Pacem in Terris todo ser humano es persona, por estar dotado de inteligencia y libre voluntad.

Larrea (2008) nos dice que hay dos clases de entes con personalidad: los de carne y hueso o físicos y los que carecen de aquellos elementos, los jurídicos, que no tienen existencia material o tangible; en este último punto retoma a Josserand. Explica que según Michuod, la persona jurídica es todo aquello que no sea hombre o ser humano, pero que puede ejercer derechos y contraer obligaciones (título XXIX del libro primero, en el artículo 564, norma civil interna).

Lacalle (2015) refiere que la dignidad humana excluye cualquier forma de utilitarismo de la persona y, siguiendo a Kant, indica que aquello que tiene un precio puede ser substituido por su equivalente, pero lo que no puede serlo, dado que no cuenta con equivalencia, tiene dignidad; por ende, las personas jurídicas, públicas o privadas, con o sin ánimo de lucro, carecerían de dicha «dignitas».

Díaz (2004), mencionando a González Casanova, Chomsky o Petras, plantea que los derechos humanos implican una lucha contra el neoliberalismo, siendo menester proteger las personas de la «discriminación, la exclusión y la miseria», todo lo cual, sin dudas, vulnera sus derechos fundamentales, conceptos aquellos inaplicables respecto de las personas jurídicas.

\section{De los derechos fundamentales y las personas jurídicas}

En Alemania, España y Colombia se les conceden derechos fundamentales a las personas jurídicas. En el primer caso, ello ha obedecido a un mandato superior, pero, en los otros dos escenarios han sido los Tribunales Constitucionales quienes han concluido que ello es procedente; pero, como interpretar no implica modificar, se cierne sobre estos Tribunales la carga de motivar razonada y lógi- 
camente el por qué asumen esta u otra posición, más aún en un tema medular como lo son los derechos humanos y fundamentales.

Díaz (1989), cuando aborda el análisis de los derechos fundamentales de las personas jurídicas públicas en España, aclara que su Tribunal Constitucional los acepta, ya que amplía el campo de protección de derechos, reconoce que es un argumento forzoso, dado que el titular de derechos es el ser humano y esto es así, ya que se busca defender los de las personas naturales miembros de la respectiva institución.

El recurso de amparo en España (Pérez, 2011) es un verdadero proceso jurisdiccional y al referir a Sierra Domínguez, sería el correspondiente con la «acción de tutela» colombiana que busca proteger derechos fundamentales amenazados o vulnerados.

Por su parte, López-Jurado (1991), refiriéndose al ámbito germano, reitera que los derechos fundamentales surgen como límites otorgados a los hombres (como género) para oponerse a la autoridad del Estado, siendo un contrasentido que algo sea y no sea al mismo tiempo, es decir: «darle al Estado herramientas para que enfrente consigo mismo», lo cual implicaría un absurdo jurídico. En España se condiciona el recurso de amparo en las personas jurídicas siempre que se trate de prerrogativas acordes con los fines para los cuales fue creado dicho ente no natural y que con ellos se garantice su existencia propia (Carballeira, 2002).

Entonces, simple y llanamente diremos que, como ocurre en estos dos países europeos, en el nuestro también se reconocen derechos fundamentales a las personas jurídicas, incluso a las de derecho público, por interpretación extensiva que hiciere nuestra Corte Constitucional (Sentencia SU-182 de 1998, Relatoría Corte Constitucional, Bogotá D. C., Colombia, revisión: 12/2/18). Solo que no por mandato normativo (Alemania) sino por interpretación jurisprudencial (España). Lo que interesa en este escenario es tratar de resolver la duda sobre las motivaciones, las razones, las justificaciones y los argumentos que se nos dan para llegar a una conclusión como esa y básicamente estarían referidos a esa dignidad humana como sustento de los derechos humanos o fundamentales y qué fue de ella en esa interpretación extensiva que hizo la Corte Constitucional, en el entendido de que es una característica que no se predica sino exclusivamente de las personas naturales y no de las jurídicas.

\section{De la educación en Derechos Humanos}

Caride (2009) expone que a los docentes de derechos humanos les ha faltado preocupación en el abordaje del tema, lo que dificulta su comprensión y compro- 
miso en ellos mismos. Este ideario de derechos no tiende a estructurarse, solo se teoriza sobre ellos (Escamilla, 2009), cuando su práctica debe ser el ideal en la educación; en palabras de Rosalío Wences Reza: «los derechos humanos son consustanciales a la universidad» (2009, pág. 162) y es claro que su plan de estudios debe ser abierto, para que se vaya contextualizando de conformidad con las exigencias que se le planteen (Ribotta, 2006).

La educación entra en la hipótesis que acá se plantea, buscando confrontar derechos fundamentales de personas naturales y jurídicas, pretendiendo activar una verdadera pedagogía sobre el tema que se interrogue y que cuestione a otros, para que los derechos no sigan siendo meras expectativas, apostándole a su materialización y que la educación sirva como base para ello, dado que una vez insertos estos, todos ganamos.

Pinzón (2010) concluye que en la educación jurídica es vital interrogarse por sus procesos pedagógicos, prácticas, relaciones, identificando sus «fundamentos conceptuales», visualizando que como tal, está emparentado a esa función social que se predica de la educación, pero también del derecho. Se nos ha indicado también que esa educación es fundamental para conseguir los fines del Estado y el progreso de un país; así parafrasea Contreras (2010) a González Ibáñez (2007).

De conformidad con la recomendación de 1974, es imperioso desarrollar un pensamiento crítico en los estudiantes e incentivar la capacidad de autodeterminación y del diálogo (López-Barajas y Ruiz, 2000), como defender el ejercicio de esos mismos derechos en nosotros y en los demás (Comisión de Derechos Humanos, 2012).

Tuvilla (2009) la piensa como necesaria para alcanzar una «comprensión crítica y responsabilidad social», con una metodología que estimule una educación participativa y dialógica, trayendo a colación a Olguín (1986). Por lo que la educación debe ser de calidad, como lo expone la Declaración de Jomtiem sobre Educación para Todos de 1990 (Hallak, 1999).

Parafraseando a Jorge Witker (2007), Diez de Urdanivia, Galván y Díaz (2012) demuestran que entre los retos de las facultades de derecho hoy día se tiene la tradicional «memoria», proponiéndose una metodología más participativa, al reflexionar el derecho como valor. Y tenemos a Barba (1997), quien propugna por docentes que no solo se limiten al tema intelectual, sino al afectivo y metodológico inescindiblemente ligados.

A ese tenor, Fernández (2013) concluye que al relacionar derechos fundamentales en la vida cotidiana ayuda a resolver los conflictos de manera pronta, amino- 
rando la brecha entre lo normativo y lo cotidiano, y cuando translitera a Rosa María Mujica (2002), advierte que no solamente se requiere tener conocimientos en el asunto, sino que también se debe estar convencido de la pertinencia de ellos para alcanzar una sociedad más humana, tener un compromiso afectivo y fe en los seres humanos. En palabras de Jares (2002) traídas por Mestre (2007), se tiene que la educación en derechos humanos ostenta como finalidad la defensa de la dignidad humana, la libertad, la justicia y otros, buscando transmitir valores y sirviendo de baluarte para prevenir sus posibles violaciones.

Esto que se ha venido exponiendo y sustentando, es significativo o se encuentra relacionado con el tema que se trata, dado que nuestro objetivo es hacer notar la suma importancia que tiene esa educación y los espacios universitarios en la formación de los estudiantes, pero enfocados en los de derecho. Sobre ese rol de la universidad en los derechos humanos «es por antonomasia el centro natural del libre desarrollo del pensamiento y de ideas al más alto nivel académico, podemos concluir que las unidades académicas que de ella emanen deben potenciar y perfilar al resto de la sociedad ese rol» (López, 2006, págs. 7-8), constituyéndose en la base para fortalecer la ciudadanía como eje de la democracia y de su profundización.

\section{METODOLOGÍA}

Se trata de una investigación cuantitativa de tipo cuasi experimental donde primero se diseña con base en una exhaustiva revisión bibliográfica un instrumento (más abajo presentado, anexo 1), que es validado mediante criterio de expertos. Posteriormente, se usa el cuestionario para determinar, por un lado, las concepciones de $\mathrm{N}=30$ estudiantes de último semestre de derecho de las universidades del Sinú y la UniRemington sobre derechos fundamentales y por otro, evaluar en pretest postest una estrategia formativa aplicada a 4 profesionales de derecho con los que se buscó mejorar en sus concepciones sobre los derechos fundamentales. Estas profesionales eran todas abogadas con un promedio de edad de 35 años y experiencia profesional de más de 6 años, todas trabajadoras en el sector público. Finalmente, se realizan comparaciones entre estudiantes y los participantes de la estrategia formativa.

\section{PARTICIPANTES}

\section{Los expertos para la validación}

El instrumento (anexo 1) se valida mediante el criterio de tres expertos, escogidos por su experticia y experiencia como magistrados, jueces y procuradores con prestigio regional y/o nacional (tabla 1). 
Tabla 1. Expertos para la validación del instrumento.

\begin{tabular}{|c|c|c|c|c|}
\hline Nombre & Profesión & Cargo & $\begin{array}{c}\text { Años de } \\
\text { experiencia } \\
\text { profesional }\end{array}$ & $\begin{array}{c}\text { Razones } \\
\text { de escogencia }\end{array}$ \\
\hline Experto 1 & Abogada & $\begin{array}{l}\text { Dirección } \\
\text { Ejecutiva } \\
\text { Seccional } \\
\text { Rama } \\
\text { Judicial }\end{array}$ & 15 años & $\begin{array}{l}\text { Por la experiencia que } \\
\text { esta profesional tiene en } \\
\text { el ejercicio de la carrera, } \\
\text { por su hoja de vida inta- } \\
\text { chable, porque tiene pro- } \\
\text { piedad, lo que le da } \\
\text { mayor inherencia en sus } \\
\text { funciones y porque mane- } \\
\text { ja el derecho desde el } \\
\text { ámbito administrativo. }\end{array}$ \\
\hline Experto 2 & Abogado & $\begin{array}{l}\text { Procurador } \\
\text { Judicial II } \\
\text { delegado } \\
\text { ante los } \\
\text { Tribunales } \\
\text { Superiores } \\
\text { de Distrito } \\
\text { Judicial }\end{array}$ & 26 años & $\begin{array}{l}\text { Por la experiencia que } \\
\text { este profesional tiene en } \\
\text { el ejercicio de la carrera, } \\
\text { por su hoja de vida } \\
\text { intachable, porque tiene } \\
\text { propiedad, lo que le da } \\
\text { mayor inherencia en sus } \\
\text { funciones y porque mane- } \\
\text { ja el derecho desde el } \\
\text { ámbito de intervención en } \\
\text { lo judicial como Minis- } \\
\text { terio Público. }\end{array}$ \\
\hline Experto 3 & Abogado & $\begin{array}{l}\text { Magistrado } \\
\text { Sala Penal } \\
\text { del Tribunal } \\
\text { Superior de } \\
\text { Distrito } \\
\text { Judicial de } \\
\text { Antioquia }\end{array}$ & 23 años & $\begin{array}{l}\text { Por la experiencia que } \\
\text { este profesional tiene en } \\
\text { el ejercicio de la carrera, } \\
\text { por su hoja de vida } \\
\text { intachable, porque tiene } \\
\text { propiedad, lo que le da } \\
\text { mayor inherencia en sus } \\
\text { funciones y porque mane- } \\
\text { ja el derecho desde la } \\
\text { aplicación de la justicia en } \\
\text { el ámbito penal en una } \\
\text { instancia representativa. }\end{array}$ \\
\hline
\end{tabular}


Los expertos, con una rejilla de 5 preguntas (tabla 2), evalúan cada uno de los 30 ítems con una escala Likert que va de 1 a 5, donde 1 es la menor puntuación. Hay un espacio para observaciones generales muy importante para el ajuste de los ítems que los expertos consideren que deben mejorarse.

Tabla 2. Preguntas para la validación mediante criterio de expertos.

\begin{tabular}{|c|l|l|l|l|l|}
\hline Preguntas para la validación & $\mathbf{1}$ & $\mathbf{2}$ & $\mathbf{3}$ & $\mathbf{4}$ & $\mathbf{5}$ \\
\hline 1) ¿Ha respondido con seguridad? & & & & & \\
\hline 2) ¿El ítem parece bien construido? & & & & \\
\hline 3) ¿Entre las opciones no está la respuesta correcta? & & & & \\
\hline 4) ¿Le parece que hay más de una respuesta correcta? & & & & \\
\hline 5) ¿El ítem le parece mal construido por motivos diferentes? & & & & & \\
\hline
\end{tabular}

6) Si tiene una observación final, realizarla aquí:

\section{Estudiantes del estudio de concepciones}

Cuando se tiene el instrumento validado por criterio de expertos, el paso a seguir es pasarlo a $\mathrm{N}=30$ estudiantes de dos universidades colombianas, Universidad del Sinú y la UniRemington, para observar si el cuestionario es comprensible y además analizar las concepciones de estos participantes. Son alumnos de carreras de derecho que están entre noveno y décimo semestre. La edad promedio es de 26 años.

\section{Los profesionales de la formación}

En la tabla 3 se observan los participantes escogidos de manera intencional en la estrategia formativa; se trata de abogadas que tenían cercanía con los autores de esta investigación. Son abogadas tituladas, con un promedio de edad de 36 años, entre 31 la menor y 45 la mayor, con conexiones con el ámbito del Poder Judicial, dado que 2 laboran para la Rama Judicial, una es fiscal y la restante litiga, es decir, actúa ante el mismo poder. Son personas conocedoras del derecho. 
Tabla 3. Participantes de la estrategia.

\begin{tabular}{|l|l|l|l|l|}
\hline \multicolumn{1}{|c|}{ Entidad } & Nombres & Edad & Profesión & \multicolumn{1}{c|}{ Entidad } \\
\hline $\begin{array}{l}\text { Fiscalía General de la } \\
\text { Nación }\end{array}$ & Adriana & 45 & Abogada & $\begin{array}{l}\text { Fiscalía General de la } \\
\text { Nación }\end{array}$ \\
\hline $\begin{array}{l}\text { Rama Judicial del } \\
\text { Poder Público }\end{array}$ & Carolina & 31 & Abogada & $\begin{array}{l}\text { Rama Judicial del } \\
\text { Poder Público }\end{array}$ \\
\hline Independiente & Yudy & 36 & Abogada & Independiente \\
\hline $\begin{array}{l}\text { Juzgado Civil } \\
\text { Municipal }\end{array}$ & Esperanza & 32 & Abogada & $\begin{array}{l}\text { Juzgado Civil } \\
\text { Municipal }\end{array}$ \\
\hline
\end{tabular}

\section{EL INSTRUMENTO PARA EVALUAR CONCEPCIONES SOBRE DERECHOS FUNDAMENTALES}

El instrumento consta de $\mathrm{N}=30$ ítems con tres opciones de respuesta, donde una es considerada como correcta sobre la formación recibida en el tema de derechos fundamentales para cualquier profesional o estudiante en derecho (anexo 1). El cuestionario se construye, primero haciendo un análisis general sobre los derechos fundamentales, en el entendido que se debía tener en claro qué y quiénes son las personas jurídicas, pero antes de ello se revisa en la bibliografía quiénes son las personas naturales. Se indagó sobre el sustento fáctico/jurídico de los derechos humanos y de los fundamentales, conectar ambas instituciones tanto de las personas naturales como de las jurídicas y en el entendido que en ambos casos se cimentaban en la dignidad humana, hubo que cuestionar sobre dicha relación.

Para abordar el punto neurálgico del asunto, referido a ese presunto vacío conceptual y argumentativo en el derecho interno colombiano, respecto de la concesión u otorgamiento de derechos fundamentales a las personas jurídicas, se hizo una revisión de estas figuras, buscando entender no solo ambas instituciones de derecho, sino también los dos tipos de personas. Se indagó el origen de los derechos y la conexión con sus titulares, y se llegó a la dignidad como sustento de estas, tanto de los humanos como género, como de los fundamentales como especie. Pero al mismo tiempo, estudiando la dignidad humana, nos percatamos de que, de acuerdo a la Corte Constitucional, encargada de interpretar la Carta Política, se han dado dos interpretaciones diametralmente opuestas: por un lado, que el fundamento de los derechos (humanos o fundamentales) es la dignidad humana; pero, por otro lado, nos dice que las personas jurídicas no pueden tener dignidad humana, por no ser miembros del género humano. 
Para abordar estos temas se plantearon 30 preguntas (anexo 1) con opciones de 3 respuestas $(\mathrm{a}, \mathrm{b}$ y c), pero una sola respuesta válida: las otras dos podríamos demarcarlas como plausibles, cercanas a la real, pero en todo caso menos acertadas. Las respuestas consideradas como correctas son las siguientes: 1) c, 2) c, 3) b, 4) a, 5) a, 6) a, 7) b, 8) a, 9) b, 10) c, 11) c, 12) a, 13) a, 14) c, 15) c, 16) $a, 17) b, 18) b, 19) c, 20) c, 21) a, 22) b, 23) a, 24) c, 25) c, 26) c, 27) a, 28) a, 29)$ c, 30) c.

Un ejemplo de pregunta es la siguiente:

2. Los Derechos Humanos según el derecho internacional son:

a) Aquellos que pactan los partidos políticos.

b) Los que reconoce la Carta de las Naciones Unidas.

c) Los que devienen de los tratados internacionales (correcta).

\section{ESTRATEGIA FORMATIVA PARA MEJORAR CONCEPCIONES SOBRE DERECHOS FUNDAMENTALES}

Se diseña una estrategia formativa de 8 horas de duración (tabla 4) para trabajar los derechos fundamentales y se invita a 4 profesionales de derecho a cursar esta propuesta que es evaluada en pretest y postest, con el instrumento en cuestión (anexo 1). La formación está desarrollada en un contenido programático donde están consignadas las 8 horas de formación: una hora era para la aplicación del instrumento presentado anteriormente (anexo 1); 2 horas para cada sesión para abordar estas temáticas, las cuales están enfocadas a abordar un caso real para incentivar el debate entre los participantes, por ello, cada sesión tiene unas preguntas que motivan la reflexión. Se finaliza aplicando el instrumento (anexo 1) en postest.

Tabla 4. Contenido programático de la estrategia formativa.

\section{Competencias a desarrollar:}

1.1. Competencia genérica de la estrategia: Desarrollar en los involucrados en el proceso educativo en derecho herramientas cognoscitivas suficientes para que puedan abordar y confrontar determinados asuntos y examinar los relativos a los derechos humanos y fundamentales dentro de los roles que deban ejecutar en sus respectivos ejercicios profesionales, más puntualmente en lo que respecta a su materialización y connotaciones en las personas jurídicas. 


\section{Aplicación del instrumento (anexo 1)}

\section{Estructura temática y desarrollo de los casos}

\section{Sesión 1: Caso núm. 1: Pedro Pablo Pérez Pereira vs. Confederación de Fun- cionarios Judiciales.}

\section{Tema: La persona natural y la jurídica.}

Descripción del caso 1: En el marco de las políticas que pretende implementar el nuevo gobierno y que involucran la conformación de una única Corte Suprema de Justicia, la cual absorbería las funciones constitucionales, contencioso-administrativas, disciplinarias y de autogobierno, ante las oposiciones que al respecto tienen los miembros de la Rama Judicial pero muy específicamente los socios de la Confederación de Funcionarios Judiciales, quienes se muestran en total desacuerdo con dicha posibilidad, se determina por esta institución que se ejecutaría un cese de actividades indefinido pero intermitente hasta que se logre su cometido consistente en obligar al gobierno a echar para atrás dicha determinación o que, por lo menos, se sienten en una mesa a analizar los pormenores de la misma. Así las cosas, se tiene que empiezan a materializarse los paros implicando obstaculizar el ingreso a los edificios más emblemáticos donde se realiza la actividad judicial, impidiendo la admisión de cualquier clase de personas, trátese de empleados, funcionarios o usuarios, y solo se lo permiten al personal de aseo y a los miembros de seguridad privada. Como se ha de suponer, esto se decidió unilateralmente por las directivas de la Confederación de Funcionarios Judiciales y entre lo resuelto se dijo que se permitiría tan solo el ingreso de tutelas con medidas cautelares, a fiscales y jueces de control de garantías (y a sus respectivos empleados) por la inherencia de estas actividades. Basados en esta coyuntura, el juez primero penal municipal con funciones de control de garantías de la ciudad, Pedro Pablo Pérez Pereira, siguió asistiendo a su jornada laboral ordinaria comprendida entre las 6 a. m. a las 2 p. m., pero cada vez que llegaba le impedían el paso pretextando el susodicho paro judicial. Al inquirir por qué no le permitían el ingreso si supuestamente por su cargo era uno de los pocos excepcionados, los delegados de la Confederación le contestaban que le tocaba esperar a que entregaran la lista del Centro de Servicios para permitírselo. En esas lides, le autorizan el ingreso pasadas las 8:30 a. m., lo cual obviamente afecta su gestión y su desempeño laboral dado que precisamente entre las 6 a. m. y las 8 a. m. es que el juez se dedica a revisar las tutelas, los incidentes de desacato $y$ las actividades administrativas, ya que regularmente luego de esa hora inician las audiencias de garantías y, por ende, no puede hacer más tarde la primigenia e igualmente obligatoria actividad. En consecuencia, el juez Pérez Pereira se debe quedar junto con su equipo de trabajo por muchas más horas luego de haber finalizado su jornada oficial, atendiendo aquellas actividades 
que no pudo dentro de la misma por el impedimento que ejerció la Confederación de Funcionarios Judiciales. Esto se reitera en el tiempo e implica que a la larga el juez deba llevarse trabajo para su casa, no pudiendo descansar como es debido, lo cual afecta, además, su salud física y mental. Es por ello, entonces, que el juez Pérez Pereira radica una tutela en contra de la Confederación buscando el amparo de sus derechos.

\section{Preguntas para la reflexión en gran grupo en clase:}

A. ¿Considera usted que ha existido confrontación de derechos fundamentales en este caso? Sea cual fuere su posición, explique cuáles serían las razones de la que adoptó. En caso afirmativo, enuncie cuáles serían y las razones de ello.

B. ¿Qué solución daría al problema jurídico que allí se le está planteando sin hacer uso de ningún apoyo extra más allá del postulado, de sus conocimientos propios y de la idea de aplicación de derecho que tiene?

C. Independientemente de su posición en la primera respuesta, sin lugar a dudas existe un choque de derechos o de perspectivas, puestos estos en balanza; ¿para usted cuál primaría y cuáles son las razones de ello?

D. ¿Qué normas, en términos generales (Constitución Política, tratados internacionales, leyes, decretos, sentencias, doctrina, etc.), utilizaría para resolver el dilema evidenciado?

\section{Sesión 2: Caso núm. 2: Andrés Arturo Arboleda Arango vs. Gestapo Kruegger.}

\section{Tema: Dignidad humana como sustento de los derechos humanos y funda- mentales.}

Descripción del caso 2: Andrés Arturo Arboleda Arango labora para la empresa Gestapo Kruegger desde enero de 2016; esta es una Sociedad Limitada de capital alemán que elabora productos metalúrgicos. Uno de los directivos de la empresa, el señor Hans Kruegger, tiene un temperamento muy fuerte, de manera que estalla en ataques de ira con suma facilidad, siendo además un convencido de la inferioridad de los pueblos latinoamericanos respecto de la suya propia (Alemania). Cree que muchos de los colombianos son ineficaces en sus labores y que no ponen el suficiente empeño, lo cual exterioriza cada vez que le es posible mediante gritos e insultos, mostrando poco recato al momento de agredir de esta manera a sus subordinados. Como ya se ha dicho, esto se ha convertido en un comportamiento cotidiano y recurrente, lo que genera malestar en el personal de trabajadores de Gestapo Kruegger, empresa legalmente 
constituida, de naturaleza privada. Estos impases también acaecen en contra de Arboleda Arango desde el primer mes en el que ingresó a laborar en dicha empresa; harto de ellos, resolvió empezar a obtener pruebas de lo que considera un maltrato o acoso laboral mediante grabaciones de video, pero además en dicho procedimiento logró también ser testigo de que las facturas de ciertos vendedores de materia prima de la empresa no eran ingresadas a los libros contables de la misma, incumpliendo una serie de normas que regulan el asunto. Es por ello entonces que decide interponer las denuncias del caso a efectos de buscar un trato digno como empleado y, además, que se lleve un proceso contable legal y legítimo. Una vez percatada Gestapo Kruegger de los hechos, y antes que el señor Arboleda Arango radique las denuncias, mediante abogado, le advierten que los videos que grabó lo fueron sin consentimiento de la empresa como tampoco del personal a ella adscrito, que lo que pretende es ilegal dado que podría verse inmerso en la conducta penal establecida en el artículo 191 del CP (ARTÍCULO 191. VIOLACIÓN EN LUGAR DE TRABAJO. Cuando las conductas descritas en este capítulo se realizaren en un lugar de trabajo, las respectivas penas se disminuirá hasta en la mitad, sin que puedan ser inferior a una unidad multa). Le exigen entonces que desista de sus intenciones, ya que en caso contrario ellos reaccionarían con la denuncia por este punible y además buscarían hacer respetar el buen nombre de la empresa, ya que lo que pretende afectaría gravemente el historial de excelente gestión corporativa que esta ha construido a lo largo de los años y que esa clase de situaciones se pueden manejar con bajo perfil sin afectar a nadie. También advierten que dicho comportamiento implicaría un incumplimiento de las cláusulas del contrato de trabajo, por lo cual sería automáticamente despedido con justa causa.

\section{Preguntas para la reflexión en gran grupo en clase:}

A. ¿Considera usted que ha existido confrontación de derechos fundamentales en este caso? Sea cual fuere su posición, explique cuáles serían las razones de la que adoptó. En caso afirmativo, enuncie cuáles serían y las razones de ello.

B. ¿Qué solución daría al problema jurídico que allí se le está planteando sin hacer uso de ningún apoyo extra más allá del postulado, de sus conocimientos propios y de la idea de aplicación de derecho que tiene?

C. Independientemente de su posición en la primera respuesta, sin lugar a dudas existe un choque de derechos o de perspectivas; puestos estos en balanza, ¿para usted cuál primaría y cuáles son las razones de ello?

D. ¿Qué normas en términos generales (Constitución Política, tratados internacionales, leyes, decretos, sentencias, doctrina, etc.), utilizaría para resolver el dilema evidenciado? 


\section{Sesión 3: Caso núm. 3: Federico Fernando Federmann Fernández vs. Migra- ción Colombia.}

\section{Tema: Razones por las que en Colombia las personas jurídicas tienen dere-} chos fundamentales.

Descripción del caso 3: El Ministerio de Relaciones Exteriores, a través de la Oficina de Migración Colombia y ante la oleada de venezolanos que cruzan la frontera buscando una vida digna, crea una estrategia que pretende no solo enfrentar dicha situación sino conjurar el riesgo que ello ha implicado desde todos los ámbitos para el Estado colombiano. Entre otras de las coyunturas que lo sustentan se encuentra la disparada de delitos contra el patrimonio económico y otros que han estado cometiendo personas de origen venezolano u organizaciones criminales compuestas de estos; por el no tratamiento de enfermedades crónicas o contagiosas de los venezolanos en su país y el coste y riesgo que ello genera para el sistema de salud colombiano que debe no solo contener la propagación de estas sino tratarlas; los desbarajustes (incluso gravables) que implica la contratación ilegal de venezolanos sin el cumplimiento de las normas mínimas laborales aprovechándose de su situación personal, dándoseles primacía respecto de los nacionales, quienes sí exigen dicho acatamiento; entre otras tantas razones. Dicha estrategia consistirá en hacer requisas en puntos neurálgicos de todas las capitales de departamentos y de ciudades intermedias para verificar los antecedentes de cada persona. Si se trata de venezolanos que no hayan ingresado legalmente al país con los respectivos trámites del caso, serán automáticamente retenidos por incumplir las normas internas, enviados a centros de paso y al día siguiente hábil, a más tardar, repatriados vía aérea a la capital vecina. Si se trata de menores de edad en las mismas circunstancias, serán entregados al ICBF para su custodia y cuidado hasta que los padres acudan por ellos para serles devueltos; si pasado un mes ello no acaece, también serán repatriados bajo las mismas condiciones que los adultos, pero se entregarán a la entidad homóloga venezolana. Ahora que si ingresaron de manera legal al país se verificará el tiempo de permanencia; si se ha superado el permitido, se les aplicará el procedimiento advertido; si no lo han superado, deberán entregar detalles de ubicación o residencia, de la actividad que se encuentran desarrollando actualmente en el país, de antecedentes penales en su país de origen y de cualquier clase de enfermedad que tengan diagnosticada para ese entonces; si se encuentran de paso, deberán informar para dónde se dirigen y cuándo partirán. Federico Fernando Federmann Fernández, ciudadano venezolano que ingresó al país por las denominadas «trochas» en abril de 2017, se encuentra laborando en un hotel de la ciudad solo con el pago del salario sin otras prestaciones y se «rebusca» otro dinero con manualidades que vende a conocidos y referidos; tiene esposa e hijos en Caracas, a los cuales les envía el grueso de dinero que recauda en esta ciudad para su manutención y para atender la grave enfermedad que sufre su madre. La 
nueva política de Migración Colombia pone en estado de alerta a Federico Fernando, quien ha llevado una vida honorable en el país, se encuentra luchando por una mejor vida para él y para los suyos, la cual no puede tener en Venezuela; no ha cometido delito alguno ni aquí ni allá y si bien es hipertenso, esto no le impide ni laborar, ni implica un perjuicio para quienes lo rodean o para el sistema de salud colombiano dado que se mantiene controlado; pero todo lo que oye le genera terror al saber que puede ser expulsado a su país de origen donde no tiene forma de subsistir ni de poder ayudar a los suyos. En ese estado de zozobra al que lo lleva la situación, deja de vender sus manualidades para evitar ser requisado, detenido y expulsado por las autoridades migratorias, lo que le implica disminución de sus ingresos y por ende de la ayuda a su familia; evita salir, casi no entra en contacto con nadie, ha perdido peso, no duerme con tranquilidad, su estado de ánimo ha desmejorado tremendamente afectando también su salud. Solicitó a Migración Colombia tener en cuenta su caso personal y que le otorgasen alguna especie de exención dado su buen comportamiento, ya que su intención no es salir del país. Esta entidad respondió que estaba representando los intereses de los colombianos, que las normas que regían dichos procedimientos se habían establecido conforme a los parámetros legales, que contaban con personalidad jurídica para actuar y que hasta el momento no existía pronunciamiento de ninguna autoridad que lo determinase de irregular, que por lo tanto, someter sus decisiones a criterios subjetivos de terceros que de hecho han cometido conductas prohibidas por la norma (como ingresar irregularmente al país) sería anular esa libertad de decisión y acción de una entidad pública que además lo hace a favor de los valores ciudadanos, junto con la seguridad y salud públicas, por lo cual no atiende su petición.

\section{Preguntas para la reflexión en gran grupo en clase:}

E. ¿Considera usted que ha existido confrontación de derechos fundamentales en este caso? Sea cual fuere su posición, explique cuáles serían las razones de la que adoptó. En caso afirmativo, enuncie cuáles serían y las razones de ello.

F. ¿Qué solución daría al problema jurídico que allí se le está planteando, sin hacer uso de ningún apoyo extra más allá del postulado, de sus conocimientos propios y de la idea de aplicación de derecho que tiene?

G. Independientemente de su posición en la primera respuesta, sin lugar a dudas existe un choque de derechos o de perspectivas; puestos estos en balanza, ¿para usted cuál primaría y cuáles son las razones de ello?

¿Qué normas, en términos generales (Constitución Política, tratados internacionales, leyes, decretos, sentencias, doctrina, etc.), utilizaría para resolver el dilema evidenciado? 


\section{RESULTADOS}

\section{Validación de los expertos}

El promedio de las tres evaluaciones de los tres expertos otorga una nota promedio de 3,3 en una escala de 1 a 5 , donde 5 es la mayor ponderación, por lo que fue necesario ajustar los ítems con puntuaciones más bajas hasta lograr que el instrumento mejorara sus calificaciones y llegara a 4, valor que asegura que se trata de un instrumento válido para evaluar concepciones sobre derechos fundamentales. Los tres expertos indicaron en la rejilla de evaluación (tabla 2, en metodología), en la opción de pregunta abierta para observaciones, cuál debería ser el ajuste que podría realizarse; así que, como generalidad de los tres expertos, se resumen los ajustes solicitados así:

- Pregunta 9: Se acogió la solicitud de cambiar la palabra «acaban» por «cesan».

- Pregunta 13: De las observaciones de los expertos, se concluye que los derechos políticos no son tutelables, pero ello no es coherente con la sistemática constitucional colombiana, dado que lo que define la condición de tutelable de un derecho no es el grupo al que pertenezca, sino su carácter de fundamental, la cual se debe analizar en su contexto y de forma particular en cada caso, de manera tal que aquello que resulte fundamental en un escenario, no necesariamente deberá serlo en otro. Sea como fuere, los derechos políticos, como votar y ser elegido, se tratan de aquellos que hacen parte de los derechos de primera generación, los cuales, por definición, son fundamentales y de extremo, tutelables; no se acoge, por tanto, el comentario.

- Pregunta 26: Los derechos fundamentales son reconocidos a nivel interno lo mismo que las personas jurídicas, no comprende la razón para un reconocimiento de estos derechos a nivel internacional. Revisada la observación, se considera que es sumamente pertinente y que la pregunta no era tan clara como se creía; así pues, se hizo una corrección buscando ser más precisos en ella.

El instrumento presentó una fiabilidad de 0,726 con el Alfa de Cronbach (valores mayores a 0,7 cercanos a 1 se consideran óptimos) que se obtuvo con el SPSS asumiendo un valor de 1 para las opciones correctas y 0 para las incorrectas como se sugiere para este tipo de cuestionarios con ítems politómicos. También se calculó la prueba KR 20 en Excel y se obtuvo un 72\% de confiabilidad del instrumento, se trata de un instrumento fiable. 


\section{Análisis de las concepciones de los estudiantes universitarios}

En la tabla 5, se observan los resultados de la aplicación del instrumento para evaluar concepciones sobre derechos fundamentales en $\mathrm{N}=30$ estudiantes universitarios. En la tabla se aprecia en columnas, los porcentajes de respuestas y las puntuaciones obtenidas para cada una de las opciones a), b) y c) del instrumento, destacándose en negrita la opción considerada correcta.

Tabla 5. Resultados de las concepciones de los estudiantes universitarios.

\begin{tabular}{|c|c|c|c|c|c|c|c|c|}
\hline \multirow{2}{*}{ Ítem } & \multicolumn{4}{|c|}{ Frecuencia } & \multicolumn{4}{|c|}{ Porcentaje } \\
\hline & A & B & $\mathrm{C}$ & SD & A & B & C & SD \\
\hline 1 & 0 & 16 & $\underline{14}$ & S/D & 0 & 53,3 & 46,7 & S/D \\
\hline 2 & 2 & 15 & 12 & 1 & 6,7 & 53,3 & 40 & 3,3 \\
\hline 3 & 4 & $\underline{20}$ & $\overline{\overline{5}}$ & 1 & 13,3 & 66,7 & 16,7 & 3,3 \\
\hline 4 & 8 & 16 & 6 & S/D & 26,7 & 53,3 & 20 & S/D \\
\hline 5 & $\underline{\underline{1}}$ & 22 & 7 & S/D & 3,3 & 73,3 & 23,3 & S/D \\
\hline 6 & $\underline{22}$ & 3 & 5 & S/D & 73,3 & 10 & 16,7 & S/D \\
\hline 7 & 2 & $\underline{16}$ & 10 & 2 & 6,7 & 53,3 & 33,3 & $6.7 \%$ \\
\hline 8 & $\underline{24}$ & 3 & 2 & 1 & 80 & 10 & 6,7 & $3.3 \%$ \\
\hline 9 & $\overline{4}$ & $\underline{17}$ & 9 & S/D & 13,3 & 56,7 & 30 & S/D \\
\hline 10 & 8 & $\overline{8}$ & $\underline{14}$ & S/D & 26,7 & 26,7 & 46,7 & S/D \\
\hline 11 & 2 & 6 & 22 & S/D & 6,7 & 20 & 73,3 & S/D \\
\hline 12 & $\underline{12}$ & 7 & $\overline{11}$ & S/D & 40 & 23,3 & 36,7 & S/D \\
\hline 13 & $\underline{\overline{8}}$ & 12 & 10 & S/D & 26,7 & 40 & 33,3 & S/D \\
\hline 14 & 0 & 9 & 21 & S/D & 0 & 3 & 70 & S/D \\
\hline 15 & 0 & 14 & $\underline{16}$ & S/D & 0 & 46,7 & 53,3 & S/D \\
\hline 16 & $\underline{14}$ & 14 & 1 & 1 & 46,7 & 46,7 & 3,3 & $3.3 \%$ \\
\hline 17 & $\overline{6}$ & $\underline{20}$ & 4 & S/D & 20 & 66,7 & 13,3 & S/D \\
\hline 18 & 0 & $\underline{15}$ & 15 & S/D & 0 & 50 & 50 & S/D \\
\hline 19 & 11 & 8 & $\underline{11}$ & S/D & 36,7 & 26,7 & 36,7 & S/D \\
\hline 20 & 4 & 5 & $\overline{21}$ & S/D & 13,3 & 16,7 & 70 & S/D \\
\hline 21 & $\underline{11}$ & 13 & $\overline{6}$ & S/D & 36,7 & 43,3 & 20 & S/D \\
\hline 22 & 13 & $\underline{6}$ & 11 & S/D & 43,3 & 20 & 36,7 & $\mathrm{~S} / \mathrm{D}$ \\
\hline 23 & $\underline{14}$ & $\overline{7}$ & 9 & S/D & 46,7 & 23,3 & 30 & S/D \\
\hline 24 & 8 & 13 & 9 & S/D & 26,7 & 43,3 & 30 & S/D \\
\hline 25 & 7 & 7 & $\underline{16}$ & S/D & 23,3 & 23,3 & 53,3 & S/D \\
\hline 26 & 4 & 11 & $\underline{15}$ & S/D & 13,3 & 36,7 & 50 & S/D \\
\hline 27 & $\underline{14}$ & 7 & 9 & S/D & 46,7 & 23,3 & 30 & S/D \\
\hline 28 & $\underline{\overline{13}}$ & 14 & 3 & S/D & 43,3 & 46,7 & 10 & S/D \\
\hline 29 & 7 & 10 & 13 & S/D & 23,3 & 33,3 & 43,3 & S/D \\
\hline 30 & 5 & 11 & $\underline{14}$ & S/D & 16,7 & 36,7 & 46,7 & S/D \\
\hline
\end{tabular}


Los análisis de los ítems se hicieron tomando los siguientes rangos: ítems cuyos porcentajes de acierto sean iguales o superiores al $70 \%$ son considerados fáciles, los que están entre el 70 y el $50 \%$ son medianamente fáciles y los que ostentan valores inferiores al $\mathbf{5 0} \%$ se calificaron de difíciles.

De la tabla 6, se identifica que:

- 5 ítems alcanzan puntuaciones iguales o mayores al 70\%, lo cual indica que un número reducido de estudiantes aciertan en las opciones consideradas correctas del instrumento.

- 8 ítems están entre el 70\% y el 50\%, lo que demuestra que las concepciones de los estudiantes podrían ser medianamente difíciles para ellos.

- 17 ítems están por debajo del 50\% de acierto, y se infiere que un número considerable que representa más del 50\% del total de los ítems son difíciles para los estudiantes.

De lo anterior se infiere que las concepciones de los estudiantes de las universidades del Sinú y UniRemington de último semestre de Derecho deben mejorarse con futuros procesos formativos, dado que no son las más adecuadas y están alejadas de los conceptos aportados por la teoría y que están sistematizados en las cuestiones planteadas por el instrumento aplicado (anexo 1).

\section{Análisis del pretest de los participantes a la estrategia formativa}

Las cuatro participantes identificadas con los nombres sin completar para guardar su confidencialidad (Adriana, Carolina, Yudy y Esperanza) superaron más del $50 \%$ de preguntas consideras como correctas (tabla 6). Yudy con el 90\%, seguida de Carolina con 70\%, Esperanza con el 66\% y Adriana con el 63\%. Se puede interpretar que se trata de profesionales con conocimientos sobre estas temáticas. De todas formas, lo pretendido de la estrategia formativa era lograr que aumentase la claridad conceptual en estos temas una vez finalizada la estrategia formativa de 8 horas.

Tabla 6. Frecuencia y porcentaje del instrumento de concepciones en pretest.

\begin{tabular}{|l|c|c|c|c|}
\hline & Adriana & Carolina & Yudy & Esperanza \\
\hline Correctas & 19 & 21 & 27 & 20 \\
\hline Porcentaje de acierto & $63 \%$ & $70 \%$ & $90 \%$ & $66 \%$ \\
\hline
\end{tabular}




\section{Análisis del postest de las participantes a la estrategia formativa}

En la tabla 7, se evidencia que las 4 participantes mejoraron sus puntuaciones con el instrumento, Yudy con el 93\%, seguida de Carolina con el 86\%, Adriana con el $80 \%$ y Esperanza con el $76 \%$. Esto puede traducirse en un éxito del curso en la mejora de sus concepciones.

Tabla 7. Frecuencia y porcentaje del instrumento de concepciones en postest.

\begin{tabular}{|l|c|c|c|c|}
\hline & Adriana & Carolina & Yudy & Esperanza \\
\hline Correctas & 24 & 26 & 28 & 23 \\
\hline Porcentaje de acierto & $80 \%$ & $86 \%$ & $93 \%$ & $76 \%$ \\
\hline
\end{tabular}

Comparación de resultados entre el pretest y postest tras el desarrollo de la estrategia formativa

Efectivamente la estrategia funcionó para mejorar en todas las participantes las concepciones que sobre los temas auscultados tenían; al confrontar estos resultados con el pre y pos (figura 1), nos encontramos en un aumento de dicho tópico que las cuatro participantes mostraron sobre los temas abordados; Adriana, mejora 5 puntos, Carolina 5, Yudy 1 y Esperanza 3.
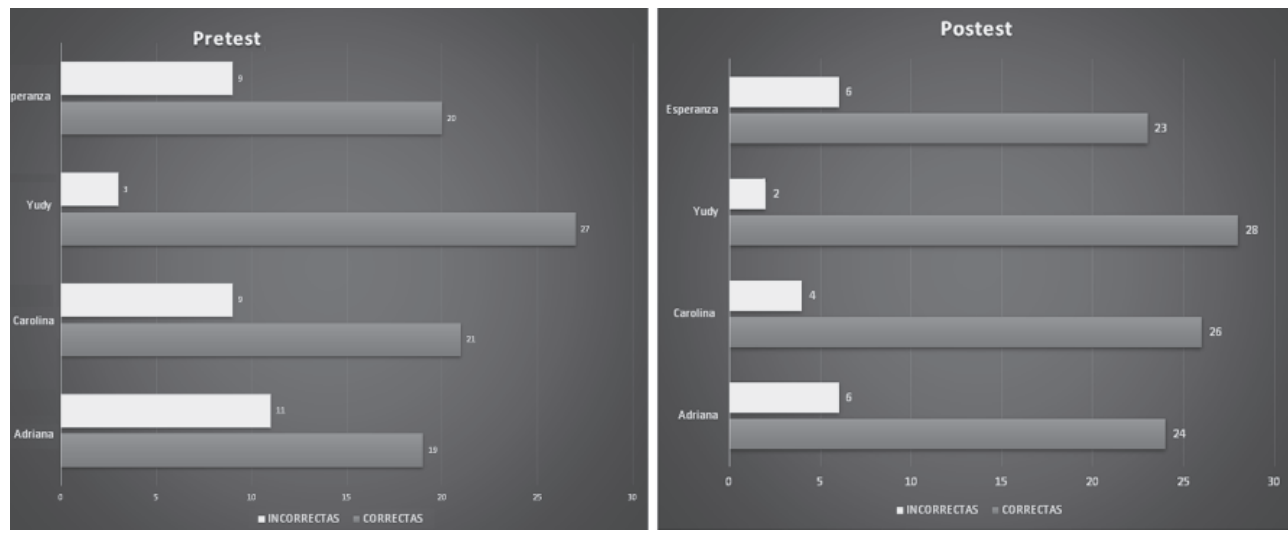

Figura 1. Comparación de resultados entre el pretest y postest.

\section{CONCLUSIONES}

La investigación surge de la necesidad de dar estructura a un problema que se evidenciaba en el ejercicio judicial al momento de tramitar amparos 
constitucionales donde se viesen inmiscuidos los derechos fundamentales de las personas jurídicas, ya que, en el entendido de que son una especie de los humanos, y que a su vez, estos solo se atribuyen de personas humanas, quedaba la confusión de las razones jurídicas para la concesión de derechos fundamentales a las instituciones que no eran seres humanos. Si bien se hallaron las respuestas a estos cuestionamientos de conformidad con los doctrinantes internacionales y en unas pocas sentencias de la Corte Constitucional, aun persistieron vacíos que no se llenan en ninguno de estos dos ámbitos dado que ambas categorías de derechos (humanos y fundamentales, es decir, género y especie) se cimentan en la dignidad humana, la cual, según interpretación constitucional, no se puede atribuir a las personas jurídicas, así la Corte Constitucional lo avale; por ende, queda confuso materialmente el porqué de darle derechos basados en la dignidad a quienes se les prohíbe dicho privilegio.

Este problema se transfiere, por tanto, al ámbito educativo, donde la falta de claridades sobre este tema según la bibliografía reportada puede ser amplio en los que ejercen el derecho; en la mayoría de los casos los abogados experimentados aplican lo que dice la Corte Constitucional, pero en los currículos universitarios no se reflexiona sobre esas incoherencias.

En esta investigación solo se pudo corroborar que las confusiones y la falta de claridades sobre estos aspectos solo ocurre en los estudiantes de último semestre de Derecho de las universidades del Sinú y la UniRemington, donde los alumnos en su gran mayoría, más del $50 \%$, eligen opciones de respuestas consideradas como incorrectas, quedando explícito que faltan claridades conceptuales. Esto, en cambio, no ocurre con los profesionales que participaron de la estrategia formativa, quienes demostraron en un inicio que tienen concepciones más adecuadas. Aunque habría que realizar estudios más finos para poder interpretar por qué ocurre esto, podría inicialmente pensarse que la experiencia profesional de las participantes de la formación al relacionarse con las temáticas pudo haber servido a la hora de enfrentarse al instrumento. Frente a esto último anotado, vale la pena mencionar que las concepciones mejoraron aún más con la formación impartida, por lo que se considera una estrategia que cumplió con sus objetivos de fortalecer las concepciones de sus participantes.

Finalmente, y con el proceso de validación mediante criterio de expertos, se puede concluir que el instrumento diseñado y empleado para identificar concepciones tanto en estudiantes como en profesionales del derecho es válido y potente para diagnosticar qué tanto saben estos actores sobre derechos fundamentales. 


\section{PROYECCIONES A FUTURO}

El instrumento debe seguir siendo aplicado a más estudiantes y profesionales del derecho y tener más datos que amplíen las conclusiones de esta investigación. Asimismo, la estrategia formativa podría en futuros procesos desarrollarse con estudiantes universitarios para ver su efecto en esta población.

\section{REFERENCIAS}

Barba, J. B. (1997). Educación para los derechos humanos: los derechos humanos como educación valoral. México: Fondo de Cultura Económica. Disponible en: http:// ebookcentral.proquest.com/lib/bibliouansp/detail.action?docID $=4559774$ yquery $=$ derechos + humanos

Barp, L. (2006). Fundamentos antropológicos de los derechos humanos. México: Red Revista del Centro de Investigación. Disponible en: http:/ / ebookcentral.proquest.com/ lib/bibliouansp/detail.action?docID=3165457yquery=derechos + humanos

Barranco, M. C. (2015). Condición humana y derechos humanos: algunas claves filosóficas para un modelo contemporáneo de derechos. Madrid: Dykinson. Disponible en: http:/ /ebookcentral.proquest.com/lib/bibliouansp/detail.action?docID=4870427y query=derechos + humanos

Blázquez, J. (2003). Dialéctica de los derechos humanos (2. ${ }^{a}$ ed.). Madrid: Dykinson. Disponible en: http://ebookcentral.proquest.com/lib/bibliouansp/detail.action? docID=3220771yquery=derechos+humanos

Bonilla, J. J. (2010). Personas y derechos de la personalidad. Madrid: Editorial Reus. Disponible en: http://ebookcentral.proquest.com/lib/bibliouansp/detail.action?doc $\mathrm{ID}=3229088$ yquery $=$ derechos + fundamentales $\}$

Carballeira, M. T. (2002). ¿Gozan de derechos fundamentales las administraciones públicas? STC 175/2001, de 26 de julio. Revista de Administración Pública, núm. 158. Pp. 233-263. Disponible en: http://ebookcentral.proquest.com/lib/ bibliouansp/detail.action?docID $=3222350$ yquery=derechos + fundamentales

Caride, J. A. (2009). Los derechos humanos en la educación y la cultura. Rosario: Homo Sapiens Ediciones. Disponible en: http:/ / ebookcentral.proquest.com/lib/ bibliouansp/detail.action?docID $=3213645$ yquery=derechos+fundamentales

Colegio24hs (2004). Los Derechos Humanos. Sin información de ciudad. Colegio24hs (Ed.). Disponible en: http://ebookcentral.proquest.com/lib/bibliouansp/ detail.action?docID $=3157754$ yquery $=$ derechos + humanos 
Comisión de Derechos Humanos (2012). Módulo de educación y derechos humanos: una propuesta metodológica para las instituciones educativas. Lima: Comisión de Derechos Humanos. Disponible en: http:/ / ebookcentral.proquest.com/lib/bibliouansp/ detail.action?docID $=4536060$ yquery=derechos + humanos

Contreras, Y. (2010). Sistema educativo y educación superior en Colombia: tensiones entre calidad y pertinencia en la escuela. Logos, Ciencia y Tecnología. Núm. 2. Pp. 94-105. Disponible en: http://ebookcentral.proquest.com/lib/bibliouansp/ detail.action?docID=3204177yquery=educaci\%C3\%B3n+en+derecho

De Asís, R. (2007). Los desafíos de los derechos humanos hoy. Madrid: Dykinson. Disponible en: http://ebookcentral.proquest.com/lib/bibliouansp/detail.action?docID= 3175816yquery=derechos + humanos

Díaz, J. M. (1989). ¿Tienen derechos fundamentales las personas jurídico-públicas? Revista de Administración Pública, núm. 120. Pp. 79-126. Disponible en: http:// ebookcentral.proquest.com/lib/bibliouansp/detail.action?docID=3223873 yquery $=$ derechos+fundamentales

Díaz, L. (2004). Globalización y derechos humanos. México: Instituto de Investigaciones Jurídicas-UNAM. Disponible en: http://ebookcentral.proquest.com/lib/ bibliouansp/detail.action?docID=3190805yquery=derechos+humanos

Diez de Urdanivia, X., Galván, M. C., y Díaz, C. (2012). Los derechos humanos en la educación jurídica. México: Plaza y Valdés, S. A. de C. V.. Disponible en: http:// ebookcentral.proquest.com/lib/bibliouansp/detail.action?docID=3218295 yquery $=$ derechos+humanos

Eggers-Brass, T., Zajac, A. M., y Gallego, M. (2004). Derechos humanos y ciudadanía. Editorial Ituzaingó: Maipue. Disponible en: http:/ / ebookcentral.proquest.com/ lib/bibliouansp/detail.action?docID=3190928yquery=derechos+humanos

Eróles, C., Gagneten, M. M., y Sala, A. (2004). Antropología, cultura popular y derechos humanos. Buenos Aires: Espacio Editorial. Disponible en: http://ebookcentral. proquest.com/lib/bibliouansp/detail.action?docID $=4498949$ yquery $=$ derechos + humanos

Escamilla, J. (2009). Los derechos humanos y la educación: una mirada pedagógica en el contex to de la globalización. México: Editorial Miguel Ángel Porrúa. Disponible en: http://ebookcentral.proquest.com/lib/bibliouansp/detail.action?docID= 3225461 yquery=educaci $\%$ C3\%B3n+en+derecho

Escobar, G. (2005). Introducción a la teoría jurídica de los derechos humanos. Madrid: Trama Editorial. Disponible en: http://ebookcentral.proquest.com/lib/ bibliouansp/detail.action?docID=3429909yquery=derechos+fundamentales 
Fayos, A. (2016). Manual de derecho civil I. Parte general y derecho de la persona. Madrid: Dykinson.. Disponible en: http:/ / ebookcentral.proquest.com/lib/bibliouansp/ detail.action?docID $=4508218$ yquery $=$ Persona + jur $\% C 3 \%$ ADdica

Fernández, M. (2013). La educación en derechos humanos en la Argentina. Buenos Aires: Editorial de la Universidad Nacional de Quilmes. Disponible en: http:// ebookcentral.proquest.com/lib/bibliouansp/detail.action?docID $=3430112$ yquery $=$ derechos + humanos

Ferrajoli, L. (2010). Los fundamentos de los derechos fundamentales (4.a ed.). Madrid: Editorial Trotta, S. A. Disponible en: http://ebookcentral.proquest.com/lib/ bibliouansp/reader.action?docID=3219274yquery=derechos+fundamentales

García, R. (2011). Los derechos sociales como derechos humanos fundamentales. México: Editorial Miguel Ángel Porrúa. Disponible en: http://ebookcentral.proquest.com/ lib/bibliouansp/detail.action?docID=3226456yquery=derechos+fundamentales

Hoyos, I. (2005). De la dignidad y de los derechos humanos. Bogotá: Universidad de La Sabana. Disponible en: http://ebookcentral.proquest.com/lib/bibliouansp/ detail.action?docID=3199341yquery=derechos+humanos

Klaiber, J., Zegarra, F., y Rubio, M. (2006). Miradas que construyen: perspectiva multidisciplinaria sobre los derechos humanos. Lima: Fondo Editorial de la Pontificia Universidad Católica del Perú. Disponible en: http:/ / ebookcentral.proquest.com/ lib/bibliouansp/detail.action?docID=3214197yquery=derechos+humanos

Lacalle, M. (2015). La persona como sujeto del derecho. Madrid: Dykinson. Disponible en: http://ebookcentral.proquest.com/lib/bibliouansp/detail.action?docID= 4508078 yquery $=$ persona + natural $+y+$ persona + jur $\%$ C $3 \%$ ADdica

Larrea, J. (2008). Manual elemental de Derecho Civil 3. Volumen 1. Nociones preliminares sobre el derecho, la ley y personas. Quito: Corporación de Estudios y Publicaciones. Disponible en: http://ebookcentral.proquest.com/lib/bibliouansp/detail.action? docID $=4945376$ yquery=persona + natural $+y+$ persona $+j u r \% C 3 \%$ ADdica

López, C. (2006). La enseñanza de los derechos humanos y del derecho humanitario en la universidad. Santiago: Red Polis. Disponible en: http://ebookcentral. proquest.com/lib/bibliouansp/detail.action?docID $=3165127$ yquery $=\mathrm{La}+\mathrm{ense} \%$ C3\%B1anza+de+los+Derechos+Humanos

López-Barajas, E. y Ruiz, M. (2000). Derechos humanos y educación. Madrid: - Universidad Nacional de Educación a Distancia (UNED). Disponible en: http:// ebookcentral.proquest.com/lib/bibliouansp/detail.action?docID $=3208243$ yquery $=$ educaci $\%$ C $3 \%$ B $3 n+e n+$ derecho 
López-Jurado, F. (1991). La doctrina del tribunal constitucional federal alemán sobre los derechos fundamentales de las personas jurídico-públicas. Revista de Administración Pública. Pp. 557-573. Disponible en: http://ebookcentral.proquest.com/lib/ bibliouansp/detail.action?docID=3224824yquery=derechos+fundamentales

Mestre, J. V. (2007). La necesidad de la educación en Derechos Humanos. Barcelona: Editorial UOC. Disponible en: http://ebookcentral.proquest.com/lib/bibliouansp/ detail.action?docID=3207101yquery=derechos+humanos

Mestre, J. V. (2016). Los derechos humanos. Barcelona: Editorial UOC (Ed.).. Disponible en: http://ebookcentral.proquest.com/lib/bibliouansp/reader.action?docID= 4570087 yquery=derechos+humanos

Morello, A. M. (2009). El derecho en la vida. La Plata: Librería Editora Platense S. R. L. Disponible en: http:/ / ebookcentral.proquest.com/lib/bibliouansp/detail.action? docID=3195974yquery=Persona+jur\%C3\%ADdica

Moreno-Bonett, M. (2004). Los derechos humanos en perspectiva histórica: de los derechos individuales a los derechos sociales 1857-1917. México: Instituto de Investigaciones Jurídicas-UNAM. Disponible en: http://ebookcentral.proquest.com/lib/ bibliouansp/detail.action?docID=3190980yquery=derechos+humanos

Nogueira, H. (2003). Teoría y dogmática de los derechos fundamentales. México: Instituto de Investigaciones Jurídicas-UNAM. Disponible en: http://ebook central.proquest.com/lib/bibliouansp/reader.action?docID=3190431yquery= derechos+fundamentales

Ollero, A. (2004). Derechos humanos: entre la moral y el derecho. México: Instituto de Investigaciones Jurídicas-UNAM. Disponible en: http:/ / ebookcentral.proquest. com/lib/bibliouansp/detail.action?docID $=3190798$ yquery=derechos+humanos

Pérez, V. (2011). La protección civil de los derechos fundamentales. Barcelona: Editorial Atelier. Disponible en: http:/ / ebookcentral.proquest.com/lib/bibliouansp/ detail.action?docID=3214113yquery=derechos+fundamentales

Pinzón, B. A. (2010). La educación jurídica como práctica de construcción social: hacia una reflexión pedagógica. Logos, Ciencia y Tecnología. Núm. 2. Pp. 63-82. Disponible en: http://ebookcentral.proquest.com/lib/bibliouansp/detail.action? docID $=3204479$ yquery=educaci $\%$ C3\%B3n+en+derecho

Prado, G. G. (2009). Los derechos fundamentales y la aplicación en la justicia constitucional. Sin información de ciudad. El Cid Editor | apuntes.. Disponible en: http: // ebookcentral.proquest.com/lib/bibliouansp/detail.action?docID=3183591 yquery $=$ derechos + fundamentales 
Ribotta, S. (2006). Educación en derechos humanos: la asignatura pendiente. Madrid: Dykinson. Disponible en: http://ebookcentral.proquest.com/lib/bibliouansp/ detail.action?docID=3175711yquery=educaci\% $\mathrm{C} 3 \% \mathrm{~B} 3 \mathrm{n}+\mathrm{en}+$ derecho

Schickendantz, C. (2009). Crisis cultural y derechos humanos. Córdoba: Editorial de la Universidad Católica de Córdoba (EDUCC). Disponible en: http:/ / ebookcentral. proquest.com/lib/bibliouansp / detail.action?docID $=3194824$ yquery $=$ derechos + humanos

Starck, C. (2010). Jurisdicción constitucional y derechos fundamentales. Madrid: Dykinson. Disponible en: http://ebookcentral.proquest.com/lib/bibliouansp/ detail.action?docID $=4498968$ yquery=derechos + fundamentales

Teruel, G. M., Pérez, A. y Raffiotta E. C. (2017). Derechos fundamentales y sus garantías jurisdiccionales. Madrid: Dykinson. Disponible en: http://ebookcentral. proquest.com/lib/bibliouansp/detail.action?docID $=4870425$ yquery=derechos + fundamentales

Tuvilla, J. (2009). Educación en derechos humanos: hacia una perspectiva global (2. ${ }^{\mathrm{a}} \mathrm{ed}$.). Sevilla: Editorial Desclée de Brouwer. Disponible en: http://ebookcentral. proquest.com/lib/bibliouansp/detail.action?docID $=3194425$ yquery $=$ derechos + humanos

Vallegas, A., Sosa, I., y Guerrero, A. L. (1994). Democracia y derechos humanos. México: Editorial Miguel Ángel Porrúa. Disponible en: http:/ / ebookcentral.proquest. $\mathrm{com} /$ lib/ bibliouansp/detail.action?docID $=4423012$ yquery=derechos+humanos

Villacorta, L., y Villacorta, A. (2013). Nuevas dimensiones de protección asumida por los derechos fundamentales. Madrid: Dykinson. Disponible en: http://ebookcentral. proquest.com/lib/bibliouansp/detail.action?docID $=3217067 \mathrm{yquery}=$ derechos + fundamentales 


\section{ANEXO 1. INSTRUMENTO SOBRE DERECHOS FUNDAMENTALES}

1. Los Derechos Humanos como categoría universal surgen luego de:

a) Las Cruzadas.

b) La Primera Guerra Mundial.

c) La Segunda Guerra Mundial.

2. Los Derechos Humanos según el derecho internacional son:

d) Aquellos que pactan los partidos políticos.

e) Los que reconoce la Carta de las Naciones Unidas.

f) Los que devienen de los tratados internacionales.

3. Los Derechos Humanos según la normativa interna colombiana son:
a) Los que se pactan con las organizaciones no gubernamentales.
b) Los inherentes a la persona humana.
c) Los que determine el Congreso.

4. Los Derechos Fundamentales desde la óptica del derecho internacional son:
a) Los reconocidos por cada Estado en ejercicio de su soberanía.
b) Los determinados por los organismos internacionales.
c) Los que reconozca la Corte Internacional de Justicia de La Haya.

5. Los Derechos Fundamentales según normativa interna colombiana son:
a) Los que establezca el orden jurídico de cualquier índole.
b) Los que reconozca la Corte Constitucional.
c) Los que devengan de los tratados internacionales de derechos humanos ratificados por Colombia.

6. Las personas naturales según normativa interna colombiana son:
a) Quienes nacen de mujer y sobreviven a la separación con su cuerpo.
b) Los fetos luego de la fecundación del óvulo por el espermatozoide.
c) Los nasciturus que superan las 9 semanas de gestación.

7. Las personas jurídicas según normativa interna colombiana son:
a) Las que alcanzan la mayoría de edad.
b) Las que se generan de acuerdo con la respectiva normatividad y para los fines establecidos.
c) Las entidades del Estado que ejercen una función pública. 
8. ¿Cuándo se da inicio a la vida de las personas naturales según normativa interna colombiana?
a) Cuando nace con vida el feto y se desprende totalmente de la madre.
b) Cuando el feto sale del vientre materno tenga o no tenga signos vitales.
c) Luego de la fecundación del óvulo por el espermatozoide.

9. ¿Cuándo finaliza la vida de las personas naturales según normativa interna colombiana?
a) Cuando es declarada interdicta judicialmente o cuando se declara la muer- te presunta por desaparecimiento.
b) Cuando cesan sus signos vitales o biológicos.
c) Cuando el médico legal así lo declara.

10. ¿Cuándo da inicio la vida de las personas jurídicas según normativa interna colombiana?
a) Cuando se firma el acta de constitución o creación.
b) Cuando finaliza la reunión interpartes de la formación.
c) Cuando se registra debidamente la misma.

11. ¿Cuándo finaliza la vida de las personas jurídicas según normativa interna colombiana?
a) Cuando entra en bancarrota o se declara en insolvencia económica.
b) Cuando es intervenida por la respectiva Superintendencia.
c) Cuando se disuelve y liquida.

12. ¿Cuáles son los Derechos que tienen las personas físicas y de qué naturaleza son según normativa interna colombiana?
a) Civiles y políticos; económicos, sociales y culturales; y medioambientales.
b) Civiles, políticos, religiosos y patrimoniales.
c) Públicos y privados.

13. ¿Cuáles son los Derechos que tienen las personas jurídicas y de qué naturaleza son según normativa interna colombiana?
a) Civiles y políticos, económicos, sociales y culturales.
b) Patrimoniales y no patrimoniales.
c) Públicos y privados.

14. ¿Cuál es la diferencia entre los conceptos de Derechos Humanos y Derechos Fundamentales según el derecho internacional? 
a) Los humanos son para hombres y mujeres sin distingo de raza y los fundamentales solo para los votantes.

b) Los humanos son para los mayores de edad y los fundamentales solo para los menores de edad.

c) Los humanos son inherentes a todo ser humano sin ninguna distinción y los fundamentales son los que reconocen los Estados.

15. ¿Cuál es la diferencia entre los conceptos de Derechos Humanos y Derechos Fundamentales según la normativa interna colombiana?

a) Los humanos son para hombres y mujeres sin distingo de raza y los fundamentales solo para los ciudadanos con derechos políticos no afectados.

b) Los humanos son para los mayores de edad y los fundamentales solo para los menores de edad.

c) Los humanos son inherentes a todo ser humano sin ninguna distinción y los fundamentales se reconocen por el Estado como ejercicio de su soberanía.

16. La diferencia de los conceptos de personas jurídicas y naturales o físicas según normativa interna colombiana obedece a

a) Las personas jurídicas son entidades incorpóreas de naturaleza pública o privada y las físicas son los seres humanos.

b) Las personas jurídicas son las empresas, sociedades anónimas o empresas de economía mixta debidamente registradas y las físicas son los ciudadanos que ejercen el derecho al voto.

c) Las personas jurídicas son las que pagan el impuesto de industria y comercio y están registradas ante la Cámara de Comercio de su ciudad y las físicas son los que se encuentran afiliados al sistema de seguridad social colombiano.

17. ¿Cuál es el sustento o fundamento jurídico de la existencia o esencia de los Derechos Humanos?
a) El nacimiento vivo de la persona.
b) La dignidad humana.
c) El reconocimiento estatal.

18. ¿Cuál es el sustento fundamento jurídico de la existencia o esencia de los Derechos Fundamentales?

a) El agotamiento de todos los trámites legislativos en el Congreso o el Poder Legislativo.

b) El reconocimiento a nivel interno y estatal.

c) Los tratados internacionales de derechos humanos. 
19. ¿Cuál es la relación entre la dignidad humana y los Derechos Humanos?

a) Los Derechos Humanos dan pie a esa dignidad humana.

b) Generan un ciclo repetitivo donde el uno da pie al otro sin importar el orden.

c) Es el soporte o cimento en el cual se fundan los Derechos Humanos.

20. ¿Cuál es la relación entre la dignidad humana y los Derechos Fundamentales?

a) Los Derechos Fundamentales dan pie a esa dignidad humana.

b) Generan un ciclo repetitivo donde el uno da pie al otro sin importar el orden.

c) Es el soporte o cimiento en el cual se fundan los Derechos Fundamentales.

21. ¿Cuál es la razón principal de hecho por la que, según el derecho internacional, se les reconoce Derechos Humanos a las personas naturales?
a) Que todo ser humano merece un trato digno.
b) Que los tratados internacionales así lo han dispuesto.
c) Que luego del Holocausto Nazi así lo pactaron los Estados soberanos.

22. ¿Cuál es la razón principal de hecho por la que, en Colombia, se les reconoce Derechos Humanos a las personas naturales?

a) Que en la Constitución de 1991 hay un acápite completo de estos derechos.

b) Que se trata de derechos anteriores al Estado.

c) Que son consecuencia de los tratados de paz luego de los varios conflictos armados internos que se han vivido en el país.

23. ¿Cuál es la razón principal de derecho por la cual, según el derecho internacional, se les reconoce Derechos Humanos a las personas naturales?

a) Que la dignidad humana es el sustento de toda norma en ese sentido.

b) Que se desarrollan en los pronunciamientos de las Cortes Internacionales y Regionales de Justicia.

c) Que han sido establecidas como tales en los tratados internacionales de Derechos Humanos.

24. ¿Cuál es la principal razón de derecho por la cual, en Colombia, se les reconoce Derechos Fundamentales a las personas naturales?

a) Así lo manda la Corte Interamericana de Derechos Humanos.

b) Se encuentran definidos taxativamente en la Constitución Nacional.

c) Su reconocimiento estatal desde cualquier índole, normativo o jurisprudencial.

25. ¿Cuál es la principal razón de hecho por la cual, en Colombia, se les reconoce Derechos Fundamentales a las personas naturales? 
a) Que representan los intereses de las corporaciones públicas.

b) Las reivindicaciones sindicalistas.

c) Que el ser humano es el fin de todo sistema jurídico y ciertos derechos son medios para lograr ese desarrollo.

26. ¿Cuál es la razón principal jurídica por la cual, según los tratadistas internacionales, se les reconoce Derechos Fundamentales a las personas jurídicas en sus respectivos países?

a) Que representan los intereses de las corporaciones internacionales.

b) Que representan los intereses de los Estados componentes de las Naciones Unidas.

c) Que representan los intereses de las personas físicas que los componen, sin interés sobre la sede nacional respectiva.

27. ¿Cómo definir la idea de ciudadanía según el derecho internacional?
a) Todo aquel nacional de un determinado país.
b) Todo aquel que tiene doble nacionalidad sin importar de qué países.
c) Todo aquel que tiene doble nacionalidad y sin antecedentes penales.

28. ¿Cómo definir la idea de ciudadanía según normativa interna colombiana?
a) Se trata de las personas que ya han cumplido la mayoría de edad.
b) Se trata de las personas que no tienen sus derechos políticos suspendidos o anulados.
c) Se trata de las personas que han votado por lo menos una vez.

29. ¿Cuáles son las razones por las cuáles a las personas jurídicas se le otorgan Derechos Fundamentales, aunque no son personas humanas?
a) Que así lo ha indicado la Corte Suprema de Justicia.
b) Que así lo determinó el código civil colombiano.
c) Que se componen de personas que ostentan estos derechos.

30. ¿Qué es un estudio de línea jurisprudencial?
a) El análisis que hace la Corte Suprema de Justicia de la jurisprudencia de las otras Cortes.
b) El estudio que hace el Ministerio de Justicia para saber cómo va a fallar una Corte en un determinado evento.
c) Es el estudio de las variantes que sobre un respectivo asunto ha tomado una Corte o una dependencia judicial a través de sus decisiones.

